\title{
Letter from the Editor-in-Chief: JIBS publication criteria and their consequences
}

\section{Lorraine Eden}

Journal of International Business Studies (2010) 41, 1093- 1098. doi: 10.1057/jibs.2010.33

\section{OVERVIEW OF JIBS 41.7}

This issue of JIBS contains eight articles that were all submitted to my editorial team; the topics span a wide range of issues in international business (IB) studies. Each article makes a valuable contribution to IB research when assessed on the JIBS three-fold criteria for publication: fit, quality and contribution. The issue opens with an article by Ambos, Andersson and Birkinshaw examining the consequences of initiative-taking in MNE subsidiaries in terms of bargaining power, autonomy and influence. Two articles on institutions and IB follow: Chacar, Newburry and Vissa on the role of home-country institutions in performance persistence research, and Kim, Kim and Hoskisson on the impact of institutional change on performance of business group MNEs in Korea. Sun, Mellahi and Thun conduct a qualitative study of political embeddedness of foreign MNEs in the Chinese automotive industry. The impact of returnee entrepreneurs, FDI and interfirm employee mobility in affecting the innovation performance of Chinese high-tech firms is studied in Liu, Lu, Filatotchev, Buck and Wright. The next two papers focus on international marketing. Dou, Li, Zhou and Su analyze relationship satisfaction between global professional service firms and their clients in China. Lastly, Sinkovics, Jean and Cavusgil examine the role played by information technology in international customer-supplier relationships in Taiwan. The issue concludes with an article by Colantone and Sleuwaegen examining the impacts of globalization through international trade flows on the entry and exit patterns of manufacturing firms in eight European countries.

\section{JIBS PUBLICATION CRITERIA AND THEIR CONSEQUENCES}

The 2010 annual conference of the Academy of International Business (AIB) was held this year in Rio de Janeiro from 24 to 29 June. Since my term as JIBS Editor-in-Chief (EIC) ends in December 2010, at this year's AIB conference I performed my last set of journal activities including the JIBS Paper Development Workshop, the JIBS Decade Award panel and my last editorial boards meeting. In thinking back to when I became JIBS EIC Elect in July 2007, I am very proud of the way my editorial team has developed new policies and procedures for the journal. Our goal for the past 3 years has been to publish insightful and influential research on IB, with the longer term strategic goal of increasing the stature and visibility of JIBS. I believe we have been successful at achieving 
these goals; although the hard evidence in terms of journal metrics will not be evident until after our term is over (Eden, 2010a).

\section{Stature of the Journal}

In terms of journal stature, perhaps the most widely used journal metric is the journal impact factor (JIF) in Thompson Reuters' Social Sciences Citation Index (SSCI). The methods Thomson Reuters uses to determine journal rankings are well respected across the academic community as being reliable and consistent, although the metrics do have their problems. Journal rankings provide hard evidence, but can be manipulated and are subject to errors. Such metrics should be taken with a grain of salt, or to continue the metaphor, the proof should be in the "pudding" that comes from actually reading the articles (Eden, 2010a).

The 2009 SSCI scores were released just before the AIB meetings. The 2-year JIF for JIBS is 3.766, up from 2.992 in 2008; the 5-year factor is 5.727, up from 5.030 in 2008 (see Table 1). These scores place JIBS as 10th in both the Business and Management categories on the 2-year ranking and 6th in Business and 7th in Management on the 5-year ranking. In addition, many papers published in JIBS are on international finance and accounting topics. If JIBS were included in the Finance category, the journal would place second in both the 2- and 5-year rankings.
The SSCI scores for JIBS have shown a remarkable upward trend over the nine years since they have been published. As Table 1 shows, the number of journals included in both the Business and Management categories increased by about $50 \%$ between 2001 and 2009. Even with the increased number of journals, JIBS has moved up roughly 10 places in the rankings, from about 20th position in 2001 to 10th position in 2009, and even higher on the 5 -year relative rankings. While the number of yearly articles published in JIBS rose about 50\% over the same period, the number of yearly cites to these articles grew almost four-fold. Part of the growth in IIBS citations reflects the recent inclusion in the SSCI of IB journals such as Journal of International Management and International Business Review, and will again next year when Management International Review finally appears, since IB authors not surprisingly publish in IB journals and cite each other. Still, the growth is impressive.

In thinking of what differentiates JIBS from the very top tier of scholarly business journals, it is useful to look at Table 2, which reports JIF scores and rankings for the top 10 journals in each of the Business and Management categories for 2009. Of this combined list of 14 journals, JIBS ranks 12th on the 2-year JIF and 8th on the 5-year JIF. Looking at the list, it is clear that almost all of the top-tier journals are mainstream discipline-based journals, tied to a large professional association. Elsewhere,

Table 1 JIBS social sciences citation index metrics, 2001-2009

\begin{tabular}{|c|c|c|c|c|c|c|c|c|c|}
\hline & 2001 & 2002 & 2003 & 2004 & 2005 & 2006 & 2007 & 2008 & 2009 \\
\hline Two-year journal impact factor & 0.866 & 1.460 & 1.393 & 1.286 & 1.250 & 2.254 & 2.283 & 2.992 & 3.766 \\
\hline Five-year journal impact factor & NA & NA & NA & NA & NA & NA & 3.333 & 5.030 & 5.727 \\
\hline Immediacy index & 0.130 & 0.023 & 0.146 & 0.581 & 0.125 & 0.173 & 0.348 & 0.320 & 0.390 \\
\hline Cited half-life & 9.4 & 9.3 & 9.3 & $>10$ & $>10$ & $>10$ & $>10$ & $>10$ & $>10$ \\
\hline Eigenfactor score & NA & NA & NA & NA & NA & NA & 0.00572 & 0.00771 & 0.00822 \\
\hline Article influence score & NA & NA & NA & NA & NA & NA & 1.188 & 1.513 & 1.493 \\
\hline Total cites & 1376 & 1653 & 1661 & 1884 & 1788 & 2554 & 3101 & 4990 & 5921 \\
\hline Number of articles & 46 & 43 & 41 & 31 & 40 & 52 & 66 & 75 & 77 \\
\hline \multicolumn{10}{|l|}{ Rank among business journals } \\
\hline Two-year journal impact factor rank & 22 & 15 & 14 & 12 & 16 & 8 & 7 & 8 & 10 \\
\hline Five-year journal impact factor rank & NA & NA & NA & NA & NA & NA & 8 & 6 & 6 \\
\hline Total number of journals & 55 & 54 & 57 & 57 & 61 & 65 & 72 & 77 & 87 \\
\hline \multicolumn{10}{|l|}{ Rank among management journals } \\
\hline Two-year journal impact factor rank & 19 & 14 & 18 & 16 & 23 & 8 & 10 & 7 & 10 \\
\hline Five-year journal impact factor rank & NA & NA & NA & NA & NA & NA & 11 & 8 & 7 \\
\hline Total number of journals & 61 & 65 & 67 & 67 & 71 & 79 & 81 & 89 & 112 \\
\hline
\end{tabular}

Source: Author's calculations from Thomson Reuters (all years, 2001-2009). 
Table 2 Top tier journals in management and business, 2009

\begin{tabular}{|c|c|c|c|c|c|c|}
\hline \multirow[t]{2}{*}{ Journal } & \multicolumn{2}{|c|}{ Five-year } & \multicolumn{2}{|c|}{ Two-year } & \multicolumn{2}{|c|}{ SSCl journal category } \\
\hline & $\begin{array}{l}\text { Journal impact } \\
\text { factor }\end{array}$ & Rank & $\begin{array}{l}\text { Journal impact } \\
\text { factor }\end{array}$ & Rank & $B \cup S$ & MGMT \\
\hline Academy of Management Review & 9.531 & 1 & 7.867 & 1 & $x$ & $x$ \\
\hline Academy of Management Journal & 9.263 & 2 & 6.483 & 2 & $x$ & $x$ \\
\hline MIS Quarterly & 9.208 & 3 & 4.485 & 5 & & $x$ \\
\hline Journal of Marketing & 8.520 & 4 & 3.779 & 11 & $x$ & \\
\hline Strategic Management Journal & 6.931 & 5 & 4.464 & 6 & $x$ & $x$ \\
\hline Administrative Science Quarterly & 6.216 & 6 & 3.842 & 10 & $x$ & $x$ \\
\hline Organization Science & 5.777 & 7 & 3.126 & 14 & & $x$ \\
\hline Journal of International Business Studies & 5.727 & 8 & 3.766 & 12 & $x$ & $x$ \\
\hline Personnel Psychology & 5.715 & 9 & 4.264 & 9 & & $x$ \\
\hline Journal of Management & 5.703 & 10 & 4.429 & 7 & $x$ & $x$ \\
\hline Journal of Retailing & 5.181 & 11 & 4.567 & 4 & $x$ & \\
\hline Journal of Consumer Psychology & 4.559 & 15 & 5.352 & 3 & $x$ & \\
\hline Journal of Operations Management & 4.178 & 19 & 3.238 & 13 & & $x$ \\
\hline Research in Organizational Behavior & 3.654 & 30 & 4.375 & 8 & & $x$ \\
\hline
\end{tabular}

Source: Author's calculations using journal impact factor from Thomson Reuters (2009).

I have referred to these journals as single-discipline or "column" journals (Eden, 2008). The Academy of Management (which owns the Academy of Management Review and the Academy of Management Journal) has over 19,000 members; the American Marketing Association (which owns the Journal of Marketing) has over 30,000 members. When compared to 3400 members in the AIB, the huge difference in size of professional associations clearly disadvantages JIBS. (Although the much smaller size of AIB may make its members more passionate about their journal than members of these behemoth associations.)

The lesson from these numbers is that a scholarly business journal that aspires to remain or even move up in the top tier of business and management journals must compete with journals that may have up to 10 times the number of potential authors and readers based on the size of their professional associations. The best - and perhaps the only - way for JIBS to compete against these odds must be to publish higher quality, more insightful and influential articles, ones that attract large numbers of authors and readers not only from within - but from outside - the AIB.

\section{JIBS Publication Criteria}

Only one journal in Table 2 spans the full breadth of all business disciplines from accounting and finance through marketing and management: the Journal of International Business Studies. JIBS is a truly interdisciplinary journal, which I elsewhere have referred to as a "row" journal (Eden, 2008), with a domain that spans all disciplines that focus on IB studies including disciplines such as geography, politics and sociology. JIBS can therefore draw from across all the various professional associations to the extent that their members share research interests in IB, and in fact this is the case in practice. JIBS sales (print institutional, site licenses, personal sales and AIB members) totaled almost 4500 subscriptions in 2009, according to our publisher Palgrave Macmillan, suggesting that about one-third of subscribers are non-AIB members. (AIB members receive the journal automatically when they join the Association.) The bulk of the non-AIB subscribers are university libraries that make JIBS available to faculty and students across campus, thus broadening the potential reach of the journal.

Interdisciplinary breadth is both strength and a weakness of JIBS. The strength and weakness aspects are easily identified when one considers the criteria for being published in JIBS. The desk reject rate for JIBS over my 3-year term has been approximately $45 \%$, with perhaps one-in-five of desk rejects being offered an invitation to revise and make a new submission. Our overall publication acceptance rate has been about $10 \%$. These two numbers (45\% and 10\%) establish the lower and upper bounds for the journal. Imagine that 10 manuscripts are submitted to JIBS each week. Of those 10, four will be desk rejected as failing to meet the minimum criteria established by the 
editorial team for external review. Of the six manuscripts that go out for review, one of the six (about 16\%) will be accepted for publication in JIBS, normally after three rounds of external review. What differentiates a submission that is desk rejected from one that is accepted?

JIBS articles must currently satisfy three general criteria to be publishable in the journal: (1) fit, (2) quality and (3) contribution. Each manuscript, when it is submitted to JIBS, goes through a threestep screening process: the Reviewing Editor (who assesses the manuscript on the basic criteria), the EIC (who also assesses manuscripts on the three criteria and assigns those that pass to an Area/ Consulting Editor) and the Area/Consulting Editor. The manuscript can be desk rejected at any of the three stages; typically the rejection is on fit or quality at the first two stages and on quality or contribution at the third stage. I outline each of these criteria briefly below.

The first criterion for publication in JIBS is fit, that is, the manuscript must fit within the domain of inquiry for the journal, which is summarized in the JIBS Statement of Editorial Policy available at http://www.jibs.net. The single most important reason why I have desk rejected manuscripts submitted to JIBS over the past three years has been lack of fit with the JIBS domain statement (which suggests to me that many authors do not read the IIBS Statement of Editorial Policy prior to journal submission).

Within the JIBS domain statement, the single most important element is the statement of what constitutes IB. My editorial team has defined IB studies as having six sub-domains, which I summarize as: (1) multinational enterprises, (2) interactions between MNEs and others, (3) cross-border business activities, (4) impacts of the international environment on businesses, (5) international dimensions of organizational forms and (6) cross-country comparative studies of business. Failure to fit within one of these six sub-domains has been the single most frequent reason for my desk rejects over the past three years. Topics that do not fall within the JIBS domain statement include, for example, studies about domestic firms in a single-country environment or teaching IB or only tangentially related to IB studies.

Because of the large number of single-country domestic studies submitted to and desk rejected by JIBS for lack of fit, the first Letter from the Editors written by my editors was on the ways that single-country studies can fit within IB studies
(Tung \& van Witteloostuijn, 2008). Five of the eight articles published in this issue of JIBS are examples of single-country studies that do successfully fit within the JIBS domain statement: Kim, Kim and Hoskisson (Korea), Sun, Mellahi and Thun (China), Liu, Lu, Filatotchev, Buck and Wright (China), Dou, Li, Zhou and Su (China) and Sinkovics, Jean and Cavusgil (Taiwan).

The second most important element in the domain statement is that JIBS is an interdisciplinary journal. Failure to consider the interdisciplinary nature of JIBS is another common reason for desk rejection. For example, submissions of purely economics or finance papers are routinely returned to authors with a request that they reframe the manuscript so as to address the wider IB context of their research and make a new submission to JIBS.

My editorial team has felt so strongly about the importance of interdisciplinary research that we also wrote a Letter from the Editors on this topic (Cheng, Henisz, Roth, \& Swaminathan, 2009). We see truly interdisciplinary research in IB studies as having three defining characteristics: (1) The research must draw on ideas and/or methods from two or more disciplines; (2) these ideas and/or methods must be integrated to produce a new and useful contribution to IB studies; and (3) the resulting product and its value-added contribution to IB studies could not have been obtained by relying on ideas and/or methods from a single discipline. At first blush, these three criteria may appear to constitute a high hurdle, discouraging some authors from submitting their work to JIBS; however, there are many ways to jump the hurdle effectively.

What interdisciplinary means, as a minimum, is being sensitive to the breadth of IB studies. Framing the paper so as to address the question: "Why should scholars from other disciplines be interested in my work?" is a first start. Authors can and should use the Introduction and Discussion sections of their JIBS submission to explicitly address the implications of their research for scholars from other disciplines. Moreover, recognizing that JIBS authors, reviewers, editors and readers come from a variety of home disciplines and speak many scholarly "languages" is helpful. For example, what may be called "multinationality" by one author may be labeled "international diversification" by another and "transnationality" by a third. Paying attention to definitions and avoiding disciplinespecific jargon are therefore important translation mechanisms. A third and most fundamental 
method is to read broadly across the disciplines on a particular topic and to integrate that research into one's own scholarship. See Cheng et al. (2009) for other methods to conduct interdisciplinary research.

The second criterion for publication in JIBS is quality. High-quality articles are rigorous, both in terms of theory development and empirical work. Manuscripts have a well-defined research question, a strong theoretical framework, testable and falsifiable propositions (or hypotheses if the paper is empirical) and discussion of critical assumptions, contrary findings and alternative explanations. If the manuscript is empirical, the methods used for both qualitative and quantitative work are leading edge in terms of best practice. When JIBS submissions are desk rejected on quality grounds it is typically because the manuscript does not have sufficient intellectual depth. This is often because the paper was submitted too early; the paper would have benefitted from additional rounds of revision after friendly review and conference presentation prior to journal submission. A second common reason for desk rejection on quality grounds is that the methods or analyses are not appropriate to the research question being asked or do not appear to be reasonably rigorous.

My editorial team has actively focused during its term on improving the quality of JIBS articles, not only as Area/Consulting Editors working with authors on their JIBS submissions, but also through activities such as writing editorials on best practices in, for example, common method variance (Chang, van Witteloostuijn, \& Eden, 2010) and student samples (Bello, Leung, Radebaugh, Tung, \& van Witteloostuijn, 2009). We have also conducted multiple Paper Development Workshops, participated in dozens of Meet the Editor panels, and managed several special issues (e.g., on innovations in IB theory, qualitative research and multilevel research) to improve the quality of IB scholarship.

The third criterion for publication in JIBS is perhaps the most difficult criterion to achieve and to assess: contribution, that is, the difference that the manuscript is expected to make to IB studies over the longer term. Contribution can be decomposed into two criteria: articles that are insightful and influential/ impactful. I see these characteristics as estimates of the long-run contribution that an article is expected to make to IB studies.

First, the manuscript must be insightful, that is, it must offer insight into (new understanding of) an existing problem or issue in IB studies. Readers should have an "A-ha! That's interesting!" moment where they recognize a new breakthrough in terms of, for example, solving a problem or making linkages between concepts. Just being interesting is not sufficient, however; the insight must also advance our knowledge of IB studies. Explicitly addressing in the Introduction and Discussion sections of the paper what the authors see as the key insights of their research can help the reader identity the core contributions. Motivating the paper by more than the "need to fill a gap in the literature" is also useful, along with clearly articulating the theoretical framework of the paper and how it builds on earlier literature.

On the other hand, dressing an article up in "new clothes" by relabeling variables or restating hypotheses is unlikely to advance our knowledge base. Testing an existing theory on a new data set may be interesting but only rarely offers new insights from the repackaging. If the insight is small, the additional contribution to knowledge will also be small. For example, slicing and dicing a research project into multiple small papers, one of which appears in JIBS, offers little in terms of building our stock of knowledge. Lack of generalizability of the research also reduces the contribution. The lesson is that authors can make their work more insightful by addressing big questions, offering new constructs or conceptualizations, and broadening the generalizability of their theories and results.

In addition to insightfulness, I also see it as critically important to JIBS that scholars think about how to make their work more influential or impactful on other scholars. Articles published in JIBS are always of high quality and insightful but not always impactful, by which I mean that other scholars find the work interesting and are influenced by the article to work on the same topic. I believe that clarity of logic and good writing are important ways to turn an insightful article into an impactful one. So too is a strong Discussion section that directly addresses how the research can be used by other IB scholars and why other scholars should want to build on this research. Addressing the interdisciplinary implications of one's research also helps to make an article more impactful by explicitly reaching out to scholars from other disciplines. Including a graph modeling the relationships among the variables is an important building block, especially valuable to those who intuitively prefer graphical over mathematical explanations. Authors should also evaluate the substantive significance of their results, not just the statistical significance, by explicitly reporting and interpreting estimates of 
effect size. A focus on substantive significance asks: "How does my research matter?" Meaningful interpretation of empirical results generates knowledge that is relevant and useful to both IB scholars and practitioners. In sum, paying attention to the impactfulness of one's paper - particularly at the last stage when the manuscript has received a conditional acceptance - should have a long-run payoff in terms of citations for the particular article, influencing the research trajectory of other scholars and building the field of IB scholarship.

\section{Consequences for JIBS}

Elsewhere, I have written on the importance of building better theories in our journals, drawing on lessons from my experience as JIBS EIC (Eden, $2010 \mathrm{~b})$. In that piece, I argue that scholars need to tell better stories and need to take the time and spend the intellectual effort do so, and I highlight several good articles on theory development. The article was written in response to Cohen (forthcoming) who argues that the international political economy journals have become boring and need "spice" added to them through perspectives, commentaries and debates. Almost all the "spicy recipes" suggested by Cohen have been put in place at JIBS over the past 10 years, and in the paper I assess their impact on JIBS. While the

\section{REFERENCES}

Bello, D., Leung, K., Radebaugh, K., Tung, R. L., \& van Witteloostuijn, A. 2009. From the Editors: Student samples in international business research. Journal of International Business Studies, 40: 361-364.

Chang, S.-J., van Witteloostuijn, A., \& Eden, L. 2010. From the Editors: Common method variance in international business research. Journal of International Business Studies, 41: 178-184.

Cheng, J. L. C., Henisz, W. J., Roth, K., \& Swaminathan, A. 2009. From the Editors: Advancing interdisciplinary research in the field of international business: Prospects, issues and challenges. Journal of International Business Studies, 40: 1070-1074.

Cohen, B. J. forthcoming. Are IPE journals becoming boring? International Studies Quarterly, 54. increased number of citations and the rising JIF scores for JIBS, as documented in Table 1, are probably partly due to these changes, I believe the real reason behind the growing stature of JIBS is the overall improvement in the quality and contribution of the articles published in the journal.

As I move into the final months of my term as JIBS EIC, let me end with an impassioned plea that authors carefully evaluate their submissions before they are submitted to JIBS in terms of our three publication criteria: fit (the articles must be both international and interdisciplinary), quality (the theory and empirical work must be rigorous) and contribution (the paper must be insightful and impactful). Putting these three ingredients together into your articles will have long-run positive consequences for JIBS - and for the field of IB studies.

\section{ACKNOWLEDGEMENTS}

I thank the members of my JIBS editorial team, both editors and board members, who have through their counsel and activities helped develop the views expressed in this editorial, which we have put in place at JIBS over the past three years. In particular, I thank Alain Verbeke, Charles Hermann and Jessica Eden for helpful discussions and comments on an earlier draft.

Eden, L. 2008. Letter from the Editor-in-Chief. Journal of International Business Studies, 39(1): 1-7.

Eden, L. 2010a. Letter from the Editor-in-Chief: Standing on the shoulders. Journal of International Business Studies, 41: 755-758.

Eden, L. 2010b. Adding spice to our scholarly journals: The JIBS experience. International Studies Quarterly, 54 903-909.

Thomson Reuters. (2001-2009). ISI Web of Science: Social Sciences Citation Index, http://thomsonreuters.com/products services/science/science_products/a-z/social_sciences_citation_ index.

Tung, R. L., \& van Witteloostuijn, A. 2008. From the Editors: What makes a study sufficiently international? Journal of International Business Studies, 39: 180-183. 